\title{
"Masculine" Describes Gender Expressions, Not Neurobiologies: Response to Dutton and Madison (2020)
}

\author{
Reubs J Walsh ${ }^{1}$ (D) \\ Accepted: 14 September 2020 / Published online: 28 September 2020 \\ (C) The Author(s) 2020
}

\begin{abstract}
This letter is a response to "Gender Dysphoria and Transgender Identity Is Associated with Physiological and Psychological Masculinization: a Theoretical Integration of Findings, Supported by Systematic Reviews" by Dutton and Madison (2020), which relies on theorisations for which substantial counter-evidence exists, fails to engage with these or other criticisms of the theories upon which it seeks to build, and reaches conclusions that contradict existing evidence. Furthermore, the original theorisations contained in Dutton and Madison (2020), and the conclusions drawn from those theorisations, risk causing serious harm to already-marginalised groups.
\end{abstract}

Keywords Gender $\cdot$ Identity $\cdot$ Transgender $\cdot$ Autism $\cdot$ Neuroimaging $\cdot$ Androgens $\cdot$ Sex $\cdot$ Masculinization

\section{Dear Editor,}

The recent publication of "Gender Dysphoria and Transgender Identity Is Associated with Physiological and Psychological Masculinization: a Theoretical Integration of Findings, Supported by Systematic Reviews" (Dutton \& Madison, 2020) casts doubt on the ability of current standards of peer-review to weed out low-quality research that harms marginalised people. In their conclusion, the authors correctly note that their theorisation of transgender identities "suggests that irreversible treatments should be very restrictively employed, as they may not resolve the underlying cause of the experienced problems, and may, instead, lead to further problems for these individuals." This is a falsifiable prediction of their hypothesis, and in fact, has already been falsified by innumerable studies showing that psychiatric outcomes for transgender patients are vastly improved by gender-affirmation surgeries (Wernick, Busa, Matouk, Nicholson, \& Janssen, 2019) and social transition (Olson, Durwood, DeMeules, \& McLaughlin, 2016). It is reasonable to assume that a significant proportion of the participants in these follow-up studies were autistic, assuming the overlap indeed exists. Furthermore,

Reubs J Walsh

r.j.walsh@vu.nl

1 Department of Clinical, Neuro- and Developmental Psychology, Vrije Universiteit Amsterdam, Amsterdam, The Netherlands although there remains a lack of specific follow-up studies with autistic people who have undergone a gender transition, the consensus among expert clinicians, most of whom are cisgender, is that although in some cases, autistic traits may complicate the patient's decision-making, and additional support is required, autism is not, in and of itself, a contra-indication for social or medical gender transition (Strang et al., 2018).

In addition to this, the idea that the brains of men and women differ for innate biological, rather than sociocultural, reasons, is hard to defend (e.g. Rippon, 2019). Despite significant and sustained efforts to identify consistent neuroanatomical correlates of sex and gender, the kinds of gross-anatomical differences discussed in the paper have not yet been established (e.g. Joel et al., 2015), and indeed, a recent study found that when gold-standard correction for sex-related differences in intracranial volume (i.e. gross anatomy of the skull itself) is used, the apparent magnitude and consistency of gender differences drops dramatically, such that machine learning (ML) classifiers perform barely above chance - at a level that could be explained by imperfections in the intracranial volume correction just as easily as by innate sex-differences (Segura et al., 2020). Relatedly, when individual traits (including both morphological and functional/ behavioural measures) are classified as "typically-male" or "typically-female", the vast majority are an unbiased mixture of "male" and "female" traits (Joel et al., 2015). Furthermore, when an ML classifier is trained on 
American participants and then tested on Chinese or Israeli participants, this drop in accuracy is once again observed (Joel et al., 2018), suggesting a role for culture in the creation of those differences that do exist. Whilst it is impossible to prove the absence of any effect, this work shows that innate sex-related effects on brain morphology and connectivity are very small if they exist at all.

The target paper barely engages with the substantial literature of evidence against the extreme male brain (EMB) hypothesis of autism aetiology (e.g. Barbeau, Mendrek, \& Mottron, 2009; Falter, Plaisted, \& Davis, 2008; Voracek \& Dressler, 2006), for example, the evidence that 2D:4D ratios do not correlate with autism measures developed by the same group that first proposed EMB (Voracek \& Dressler, 2006), and that congenital adrenal hyperplasia (in which foetal testosterone is substantially elevated) does not correspond to an increased incidence of autism (Barbeau et al., 2009). Evidence against the Blanchard typology is also ignored (Moser, 2009, 2010; Serano, 2020; Veale, 2015; Veale, Clarke, \& Lomax, 2008), for example the evidence that cisgender women experience "autogynephilic" fantasies similar or identical to those experienced by transgender women (Moser, 2009; Veale et al., 2008). There are also several factual errors, the most significant of which is probably the assertion that people assigned male at birth are overrepresented in the transgender population (Cheung et al., 2018).

Finally, therefore, the suggestion that trans people are "masculinised" based on the overlap with autism is no more valid than another of the authors' assertions that a $2 \%$ difference in the rate of left-handedness between the sexes renders handedness a meaningful correlate of sex. A more parsimonious proposition is that autistic people are more likely to identify as trans due to differences in perception and cognition leading to a reduction in the likelihood that social conditioning will prevent them from becoming aware of their gender identity when it differs from the gender assigned to them at birth (Jackson-Perry, 2020; Walsh, Krabbendam, Dewinter, \& Begeer, 2018).

Considering these numerous scientific failures, Dutton and Madison (2020) represent a perhaps-unintentional attack on a vulnerable minority which (ab)uses the power and authority of academic science to provide credibility to a pathologizing and cisgenderist theory with little-to-no scientific or academic merit.

Funding The author's employment is funded by a European Research Council (ERC Consolidator grant, grant number 648082, awarded to Lydia Krabbendam).

\section{Compliance with Ethical Standards}

Conflict of Interest The author declares that they have no conflict of interest.
Open Access This article is licensed under a Creative Commons Attribution 4.0 International License, which permits use, sharing, adaptation, distribution and reproduction in any medium or format, as long as you give appropriate credit to the original author(s) and the source, provide a link to the Creative Commons licence, and indicate if changes were made. The images or other third party material in this article are included in the article's Creative Commons licence, unless indicated otherwise in a credit line to the material. If material is not included in the article's Creative Commons licence and your intended use is not permitted by statutory regulation or exceeds the permitted use, you will need to obtain permission directly from the copyright holder. To view a copy of this licence, visit http://creativecommons.org/licenses/by/4.0/.

\section{References}

Barbeau, E. B., Mendrek, A., \& Mottron, L. (2009). Are autistic traits autistic? British Journal of Psychology, 100(1), 23-28. https://doi. org/10.1348/000712608X337788.

Cheung, A. S., Ooi, O., Leemaqz, S., Cundill, P., Silberstein, N., Bretherton, I., Thrower, E., Locke, P., Grossmann, M., \& Zajac, J. D. (2018). Sociodemographic and clinical characteristics of transgender adults in Australia. Transgender Health, 3(1), 229-238. https://doi.org/10.1089/trgh.2018.0019.

Dutton, E., \& Madison, G. (2020). Gender dysphoria and transgender identity is associated with physiological and psychological masculinization: A theoretical integration of findings, supported by systematic reviews. Sexuality Research \& Social Policy. https://doi.org/ 10.1007/s13178-020-00489-z.

Falter, C. M., Plaisted, K. C., \& Davis, G. (2008). Visuo-spatial processing in autism - Testing the predictions of extreme male brain theory. Journal of Autism and Developmental Disorders, 38(3), 507-515. https://doi.org/10.1007/s10803-007-0419-8.

Jackson-Perry, D. (2020). The autistic art of failure? Unknowing imperfect systems of sexuality and gender. Scandinavian Journal of Disability Research, 22(1), 221-229. https://doi.org/10.16993/sjdr. 634.

Joel, D., Berman, Z., Tavor, I., Wexler, N., Gaber, O., Stein, Y., Shefi, N., Pool, J., Urchs, S., Margulies, D. S., Liem, F., Hänggi, J., Jäncke, L., \& Assaf, Y. (2015). Sex beyond the genitalia: The human brain mosaic. Proceedings of the National Academy of Sciences of the United States of America, 112(50), 15468-15473. https://doi.org/ 10.1073/pnas. 1509654112 .

Joel, D., Persico, A., Salhov, M., Berman, Z., Oligschläger, S., Meilijson, I., \& Averbuch, A. (2018). Analysis of human brain structure reveals that the brain "types" typical of males are also typical of females, and vice versa. Frontiers in Human Neuroscience, 12(October), 1-18. https://doi.org/10.3389/fnhum.2018.00399.

Moser, C. (2009). Autogynephilia in women. Journal of Homosexuality, 56(5), 539-547. https://doi.org/10.1080/00918360903005212.

Moser, C. (2010). Blanchard's autogynephilia theory: A critique. Journal of Homosexuality, 57(6), 790-809. https://doi.org/10.1080/ 00918369.2010.486241.

Olson, K. R., Durwood, L., DeMeules, M., \& McLaughlin, K. A. (2016). Mental health of transgender children who are supported in their identities. Pediatrics, 137(3), 1-8. https://doi.org/10.1542/peds. 2015-3223.

Rippon, G. (2019). The gendered brain : The new neuroscience that shatters the myth of the female brain. London: Bodley Head.

Segura, C. S., Victoria, M., Gual, I., Aguirre, N., Javier, Á., Cruz, G., \& Forn, C. (2020). Effects of different intracranial volume correction methods on univariate sex differences in grey matter volume and 
multivariate sex prediction. Scientific Reports, c, 0123456789, 115. https://doi.org/10.1038/s41598-020-69361-9.

Serano, J. (2020). Autogynephilia: A scientific review, feminist analysis, and alternative 'embodiment fantasies' model. The Sociological Review, 68(4), 763-778. https://doi.org/10.1177/ 0038026120934690.

Strang, J. F., Meagher, H., Kenworthy, L., de Vries, A. L. C., Menvielle, E., Leibowitz, S., Janssen, A., Cohen-Kettenis, P., Shumer, D. E., Edwards-Leeper, L., Pleak, R. R., Spack, N., Karasic, D. H., Schreier, H., Balleur, A., Tishelman, A., Ehrensaft, D., Rodnan, L., Kuschner, E. S., Mandel, F., Caretto, A., Lewis, H. C., \& Anthony, L. G. (2018). Initial clinical guidelines for co-occurring autism spectrum disorder and gender dysphoria or incongruence in adolescents. Journal of Clinical Child \& Adolescent Psychology, 47(1), 105-115. https://doi.org/10.1080/15374416.2016.1228462.

Veale, J. F. (2015). Comments on ethical reporting and interpretations of findings in Hsu, Rosenthal, and Bailey's (2014) "The Psychometric Structure of Items Assessing Autogynephilia". Archives of Sexual Behavior, 44(7), 1743-1746. https://doi.org/10.1007/s10508-0150552-y.
Veale, J. F., Clarke, D. E., \& Lomax, T. C. (2008). Sexuality of male-tofemale transsexuals. Archives of Sexual Behavior, 37(4), 586-597. https://doi.org/10.1007/s10508-007-9306-9.

Voracek, M., \& Dressler, S. G. (2006). Lack of correlation between digit ratio (2D:4D) and Baron-Cohen's " Reading the Mind in the Eyes"” test, empathy, systemising, and autism-spectrum quotients in a general population sample. Personality and Individual Differences, 41, 1481-1491. https://doi.org/10.1016/j.paid.2006.06.009.

Walsh, R. J., Krabbendam, L., Dewinter, J., \& Begeer, S. (2018). Brief report: Gender identity differences in autistic adults: Associations with perceptual and socio-cognitive profiles. Journal of Autism and Developmental Disorders, 48(12), 4070-4078. https://doi.org/10. 1007/s10803-018-3702-y.

Wernick, J. A., Busa, S., Matouk, K., Nicholson, J., \& Janssen, A. (2019). A systematic review of the psychological benefits of genderaffirming surgery. Urologic Clinics of North America, 46(4), 475486. https://doi.org/10.1016/j.ucl.2019.07.002.

Publisher's Note Springer Nature remains neutral with regard to jurisdictional claims in published maps and institutional affiliations. 